better sexual health outcomes. There is a need for strategies to raise uptake of such edu-dramas, and to evaluate whether wider coverage leads to population impact.

Disclosure No significant relationships.

\section{P410 PROGRAM EVALUATION TO PROVIDE HIV AND STI INFORMATION IN JUNIOR HIGH SCHOOLS IN KPANDO, GHANA}

${ }^{1}$ Danielle Vos, ${ }^{1}$ Kafui Bavor, ${ }^{1}$ Edem Richard Adjordor*, 2 Laura Koster. ${ }^{1}$ HardtHaven Children's Home, Kpando, Ghana; ${ }^{2}$ UNiTED Projects, Kpando, Netherlands

\subsection{6/sextrans-2019-sti.497}

Background We are a group of young people, aged 15 to 23 in Junior and Senior High School who are living with HIV. We are starting the conversation in our community to educate youth about HIV and STI. We do this together with our sister organization UNiTED. UNiTED conducts regular health education about HIV and STI in 13 schools. As 'The STARS' we conduct activities on World AIDS Days (WAD) in 19 schools. To evaluate the impact of our activities a program evaluation took place in June 2018.

Methods The program evaluation was a survey to assess students' knowledge about health behaviors. This survey was conducted in 4 schools that did not have the UNiTED health lessons and 3 schools that did have UNiTED health lesson and were also part of the WAD activities. The tool used was a modified version of validated Knowledge Attitude Practices (KAP) survey.

Results 382 JHS students participated in this study, aged between 10 and 24 years old, with a mean age of 14.6 years old. 195 attended form 1 and 185 attended form 2. On safe sex, STIs and teenage pregnancy, the intervention group scored $1.5 \%$ higher in comparison with the control group. The intervention group scored $0.4 \%$ lower on the topic HIV/ AIDS than the control group. Both results were not significant.

Conclusion While the results from the process evaluation of STI education show that the 2017 activities did not have the desired effect of increasing knowledge about STIs in the students which took part in the WAD activities in 2017 we are using the findings of the study to better integrate UNiTED's in school education with the WAD to create synergies for learning which we hope will increase the effectiveness of the two activities. We will conduct another evaluation of knowledge secondary school student's in 2019.

Disclosure No significant relationships.

\section{P411 ACCEPTABILITY OF A PHONE APP-BASED MOTIVATIONAL INTERVIEWING INTERVENTION FOR YOUNG MEN'S SEXUAL HEALTH}

Alexis Guzman*, Sara Landers, Meredith Nechitilo, Marina Catallozzi, Melanie Gold, David Bell, Susan Rosenthal. Columbia University Irving Medical Center, Pediatrics, New York, USA

\subsection{6/sextrans-2019-sti.498}

Background Motivational interviewing (MI) is an effective communication style for facilitating behavior change. Pairing MI with a smartphone app has the potential to engage young men, a traditionally hard-to-reach population. We assessed young men's experiences in a pilot study examining the use of a smartphone app with phone-based MI coaching by trained community health coaches (one female, one male).

Methods Fourteen (of 26) predominantly black and Hispanic men, ages 16-19 years, who participated in the pilot study were interviewed about their experience. They participated in app activities and coaching that addressed sexual health or fitness (comparison group). Interviews were transcribed and coded using thematic analysis.

Results Participants found the app activities and coaching to be acceptable. In both arms, the young men were asked about sexual health and reported being comfortable discussing it in this format. In the sexual health arm, they reported gaining knowledge about contraceptive methods and sexually transmitted infections, which some shared with their sexual partners. Participants were comfortable with the coach's gender; a benefit of a female coach was her perspective on sexual health. Most preferred phone rather than in-person or video coaching sessions due to not having to travel, ease of rescheduling sessions, and increased privacy regarding sensitive subjects. The most common obstacle to participation was phone replacement; others included parental monitoring and restriction of phone privileges. Over time, the young men felt positively about their connection to the coach. They sometimes viewed the coach as having medical expertise beyond the scope of his/her training.

Conclusion Phone app-based MI with community health coaches has great potential for use with young men for a variety of health issues including sexual health; however, it has unique obstacles. Phone accessibility may restrict young men's ability to fully engage and perceptions of a coach's expertise should be regularly clarified.

Disclosure No significant relationships.

\section{P412 AN EXPLORATORY ANALYSIS OF ASSOCIATIONS BETWEEN PSYCHO-SOCIAL FACTORS AND SYSTEMIC INFLAMMATION AMONG SOUTH AFRICAN YOUTH}

\begin{abstract}
${ }^{1}$ Ashley Henry*, ${ }^{2}$ Daniel Muema, ${ }^{2}$ Ngomu Akilimali, ${ }^{3}$ Fatima Laher, ${ }^{4}$ Manjeetha Jaggernath, ${ }^{5}$ Stefanie Hornschuh, ${ }^{1}$ Patricia Smith, ${ }^{1}$ Laura Cotton, ${ }^{4}$ Mags Bekinska, ${ }^{6}$ Jenni Smit, ${ }^{3}$ Janan Dietrich, ${ }^{3}$ Glenda Gray, ${ }^{7}$ Mark Brockman, ${ }^{1}$ Angela Kaida, ${ }^{8}$ Thumbi Ndung'U. ' Simon Fraser University, Faculty of Health Sciences, Burnaby, Canada; ${ }^{2}$ Africa Health Research Institute, HIV Pathogenesis Programme, Durban, South Africa; ${ }^{3}$ Perinatal HIV Research Unit (PHRU), Faculty of Health Sciences, University of the Witwatersrand, Johannesburg, South Africa; ${ }^{4}$ University of the Witwatersrand, Maternal Adolescent and Child Health Research Unit, Durban, South Africa; ${ }^{5}$ University of the Witwatersrand, Faculty of Health Sciencesperinatal HIV Research Unit (PHRU), Johannesburg, South Africa; ${ }^{6}$ MatCH Research Unit $(M R U)$, Department of Gynecology and Obstetrics, Faculty of Health Sciences, University of

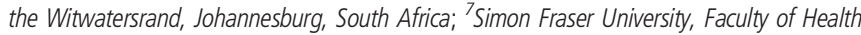
Sciences, Burnaby, Canada; ${ }^{8}$ University of the KwaZulu Natal, HIV Pathogenesis Programme and Africa Health Research Institute, Durban, South Africa
\end{abstract}

\subsection{6/sextrans-2019-sti.499}

Background Psycho-social factors affect biological processes, including inflammation and immune response, yet their contribution to gender and socio-economic disparity of HIV is not well understood. In South Africa, 38\% of new HIV infections occur in 15-24 year olds, with 3-times higher incidence among females. In this exploratory study, we examined associations between psycho-social factors and biomarkers of inflammation that may be linked to HIV acquisition in South African youth.

Methods Baseline plasma and linked cross-sectional survey data were obtained from the AYAZAZI study, which enrolled 425 HIV uninfected or HIV status-unknown youth (16-24 years 